\title{
Group Psychotherapy with Ethnoracially Diverse OEF/OIF/OND Veterans Presenting with Comorbid Psychopathology: A Transdiagnostic Clinical Forensic Paradigm
}

\author{
Johnson $\mathrm{R}^{* 1}$, Li $\mathrm{J}^{2}$ and Chapman $\mathrm{M}^{3}$ \\ ${ }^{1}$ Department of Psychiatry, VA Nebraska-Western Iowa Health Care System, Creighton University School of Medicine, \\ CA, United States \\ ${ }^{2}$ University of San Diego, CA, United States \\ ${ }^{3}$ Department of Psychiatry, Creighton University School of Medicine, Nebraska, United States
}

${ }^{*}$ Corresponding author: Johnson R, Department of Psychiatry, VA Nebraska-Western Iowa Health Care System, Creighton University School of Medicine, CA, United States, Fax and Tel: 402-994-4344, E-mail: ronnjohncts@gmail.com

Citation: Johnson R, Li J, Chapman M (2017) Group Psychotherapy with Ethnoracially Diverse OEF/OIF/ OND Veterans Presenting with Comorbid Psychopathology: A Transdiagnostic Clinical Forensic Paradigm. J Forensic Sci Criminol 5(4): 401

Received Date: December 22, 2016 Accepted Date: August 22, 2017 Published Date: August 23, 2017

\begin{abstract}
The comorbid psychopathology that is well-established in ethnoracially diverse OEF/OIF/OND veterans also often coincides with other problems (e.g., legal and social). To mitigate the clinical side of these types of difficulties, the Veteran Administration Health Care Systems offers a wide range of mental health services. This article draws on an evidenced-based literature review to explore factors that are relative to delivering group psychotherapy in light of the entwined clinical and forensic matters sometimes confronting diverse veterans.
\end{abstract}

Keywords: Psychotherapy; Psychiatry; Forensic psychology

\section{Introduction}

Group psychotherapy may be viewed as one of the most frequently used and is an evidenced-based approach for treating mental disorders. OEF/OIF/OND veterans are a ethnoracially diverse collection of mental health causalities who are clinically primed to benefit from therapeutic groups. The casualty examples are probably best understood through the life accounts chronicled by the children of veterans For example, forensically, the stark family reality is echoed in the adverse experiences that can be noted when a veteran becomes involved in child custody or visitation case. Married soldiers comprise more than one-half of the U.S. military [1]. In addition, for the 2.1 million troops that have been deployed during OEF/OIF/OND conflicts, $44 \%$ of them are parents [2]. As a result, the aforementioned numbers mean that signs of a stressful breakup process endured by families are expected to be well-represented in the clinical treatment and forensic-relevant assessments conducted during various service phases from predeployment through post-military psychosocial adjustments [3,4]. To no surprise, while the prevalence of diagnosable mental disorders is strikingly high in OEF/OIF/OND veterans, it is these same psychological factors that are also predictably highlighted during a review of their issues pertaining to parental-related conduct. For example, OEF/OIF veterans with dependent children were about $40 \%$ more likely to carry a diagnosis of PTSD.

The professional demands emerging from child custody or visitation cases of veterans overlap the practice domains of clinical and forensic psychology (i.e., psycho-legal). However, there is a paucity of professional resources specifically devoted to OEF/ OIF/OND veterans in relation to their child custody and visitation issues and much less on the role that group psychotherapy can play. There are information sources for custody evaluations that have been developed by several professional organizations (e.g., American Psychological Association, 2010; American Academy of Child and Adolescent Psychiatry, 1997) [5]. Despite the availability of this information, there is comparatively little guidance that specifically cements a firmer understanding of the nexus between a psycho-legal decision and the need for an unbiased assessment of the adjustable impact of accumulative stressors on veterans with respect to child custody or visitation. Behaviors observed or not observed by the provider of these veterans during group psychotherapy could be particularly relevant in their various legal cases. Veteran Courts are cropping up to address the myriad of needs presented by veterans when there are legal matters. Child custody and visitation is used as just one example of the 
types of legal entanglements among others (e.g., substance abuse and relational violence, etc.) where clinical forensic issues might also be problematic for OEF/OIF/OND veterans.

In a balanced child custodial and visitation clinical forensic debate, there are aggravating and mitigating effects for veterans as a result of their military service (e.g., applying skills acquired in training, discipline, and a fulfilled sense of duty [6]. Unfortunately, for a sizable group of veterans, the stress stemming from military service can also result in the development of, or exacerbation of, psychological concerns that are noted during these parental disputes. Moreover, these subsequent mental health issues are more likely to be trumpeted as particularly relevant to consider for those military personnel exposed to combat zones [7-10]. Disappointingly, for some veterans the symptoms can last 20 years or longer following their service [11]. In fact, the post-service experiences of military families can reveal a portrait of relational discord that often leads to divorce or separation [1]. To make matters worse, there is the regular stress of everyday living that is coupled with other stirring family relational difficulties (e.g., mental illness in the non-military partner) that are predictably exacerbated by deployment separation, reintegration return issues or an honorable discharge of a veteran [12-14]. As a result, one of the markers of being in a veteran's family is the almost seamless flow into an evolving need to deal with child custody and visitation matters. For example, the stressors of infidelity, PTSD, and other severe injuries (e.g., mTBI and TBI) can erode family relational connections to a point that can logically result in dissolution. In terms of relevant numbers, Flake, Davis, Johnson, and Middleton (2009) evaluated the psychological risk of deployment on a child between the ages of 5 and 12 [15]. They found the percentage of children at risk was 2.5 times higher than national norms. A large percentage (42\%) of the non-deployed parents experienced substantial levels of distress. To little surprise, the children of parents with such high levels of stress were about seven times more likely to score at high risk for psychosocial problems. There is essentially a linear relationship between family dissolution, military experiences and subsequent disputes over child custody and visitation. Forensically, the turbulent child custody and visitation process is ostensibly aimed at crafting at a blueprint that spells out who has the power to make decisions as well as a plan for sharing time with the child. Sharing is an indispensable part of child custody and visitation despite the blatantly harsh things that occur during the relational dissolution process for veterans.

Evidenced-based group psychotherapy conducted during or after the dissolution must function in a clinical forensic context that works to promote a veteran's fitness and propriety as a parent that would merit full consideration for child custody and visitation. For example, group psychotherapy can work to mitigate concerns about a veteran's ability to care for their children despite any disability by providing relevant information about the patient's functioning within the context of group. Moreover, if it is psychologically feasible, a natural outcome deriving from this clinical forensic approach to practice is the provision of clear and convincing evidence that refutes or offers mitigating group psychotherapy information that is relevant to any charge that military service has compromised or somehow limited their ability to care for minor children or otherwise provide for their diverse developmental needs. It is self-evident that an OEF/OIF/OND veteran's family circumstances can contain heightened concerns that signal potential instability across time and context. Nonetheless, at the same time it cannot be universally acceptable to operate in any manner that suggests that most of the issues (e.g., specific mental, physical, behavioral, and functional health) pertaining to the veteran in question are solely negatively correlated with respect to their capacity to adequately function under the terms of a reasonable but legally enforceable child custody or visitation plan.

This article argues that OEF/OIF/OND veterans present with comorbid psychopathology that is inextricably intertwined with a wide assortment of legal issues (i.e., clinical forensic). These cases may be plagued by a critical absence of information that functions to narrow exceptions to a broad range relevant issues for OEF/OIF/OND veteran cases. To correct this failure, this article presents additional veteran considerations specifically on the of group psychotherapy with respect to better informing the psycho-legal decision making in this regard. First, there is a review of an inconvenient group psychocultural portrait of OEF/OIF/OND veterans. Second, a section is devoted to examining expanding a clinical-forensic "What Works Paradigm" for treating psychopathology. Third, a group treatment nexus for communicating to court on behalf of veterans is explored. Fourth, is a question of the coverage of provider preference-selection treatment factors more of a non-issue for Veterans? Fifth includes ethical-legal issues and culturally responsive considerations for group psychotherapy. Finally, implications for clinical forensic group psychotherapy practice, research and training are highlighted.

\section{An Inconvenient Psychocultural Group Portrait of OEF/OIF/OND Veterans}

Since 2001 the United States has deployed over 2 million service members to various military campaigns that include Iraq and Afghanistan [16,17]. As a result, service members unfortunately return home with an unwanted mixture of mental health conditions and other disabling conditions. Also, despite the health services provided by the VA, there are remaining gaps in accessibility and mental health care that must be ameliorated [16].

Multiple studies have presented findings indicating a high prevalence of mental disorders among veterans [18,19]. For example, Trivedi et al. (2015) discovered that out of approximately 4.4 million veterans who were seen through the VHA, about 1.1 million were diagnosed with at least one (or co-occurring) disorder like PTSD, substance use disorder, depression or anxiety [18]. Other serious mental illnesses included mood disorders and schizophrenia. Not only is it prevalent, but the co-occurring disorders, which are harder to treat, is often what can be found and assessed in many veterans. The symptoms from depression, generalized anxiety disorder, substance use, bipolar disorder, and PTSD are examples of disabling psychological conditions, which can lead to a high rate of suicidal ideation [18]. The impact of psychological trauma and mental disorders on US veterans is not only debilitating but costly from a public health perspective [20]. 
Journal of Forensic Science \& Criminology

OEF/OIF/OND veterans are more vulnerable to developing PTSD due to repeated exposure to traumatic stressors during a longer period [21]. Several other variables also add to the psychological trauma experienced by veterans and have concomitant symptoms not better described by depression, anxiety, post-traumatic stress, and substance use disorder, as a tendency to selfmedicate $[18,22]$. There is a growing concern about self-assessed patients who may have rendered their own diagnosis or refused the prescribed treatment. The aforementioned discussion does not adequately take into consideration other comorbid medical or environmental factors that may exacerbate a mental disorder, for instance, mild traumatic brain injury (mTBI), other pain-related conditions, or homelessness [23-25]. For instance, the methods of assessment of combat among OEF/OIF/OND service members have demonstrated higher rates of reported TBI, complicating treatment when comorbid with another mental disorder [17].

The psychocultural portrait becomes even more troublesome when it reveals that OIF/OEF veterans are about at $18 \%$ at risk to have developed PTSD by the time they have returned home from deployment (PTSD.VA). Further, a report by the Institute of Medicine in 2012 found that recent estimates of PTSD being diagnosed among OEF/OIF veterans Ranged from 13 to 20\% [26]. These numbers are staggering when compared to a 7.8\% prevalence rate for PTSD is estimated in the general population who has experienced traumatic stress [27]. PTSD and its impact create barriers in an individual's life regarding daily performances. There are also forensic psychological issues as veterans come into direct contact with legal authorities for a wide range of reasons. As a result, a significant number of veterans with PTSD, depression and anxiety to no surprise also experience interpersonal challenges, unemployment, physical ailments and other instabilities in relationships [27,28]. The barriers to seeking care among veterans are partially influenced by stigma, beliefs about mental health, and it is intensified within the military culture [22]. Most veterans choose to keep their symptoms and challenges to themselves or within the family (PTSD.VA) [18]. However, the aforementioned clinical disorders underscore the need for evidence-based treatment for comorbid psychopathology.

\section{Expanding a Clinical Forensic "What Works Paradigm for Group Treatment of Co-Morbid Psychopathology"}

A Transdiagnostic clinical forensic paradigm for the work with OEF/OIF/OND veterans is often complicated by co-occurring psychiatric disorders, particularly PTSD. Patients with PTSD also often report one or more difficulties like extreme anxiety and major depressive disorder symptoms. In some cases, the nexus between PTSD and depression may be a reciprocal one, with each condition potentially influencing the other in some respect. As a result, the increased occurrence of comorbidity coupled with evidence suggesting moderating effects of each condition on the other, reinforces the clinical notion that treatments focused on both comorbid conditions are more likely than not going to produce improved clinical results. Despite this understanding of comorbid conditions there remain inherent difficulties in efforts to coordinate the treatment of these patients. A major issue is the tendency for a more circumscribed approach to the treatment that fails to adequately consider the relationship between the psycho-legal issues and ignoring the full potential benefit that group psychotherapy can provide these patients. For example, some providers are prone to fail to appreciate the full context of the clinical forensic circumstances confronting the patient. There is even much less understanding of how group psychotherapy offers an expanded information source of patient behavior that would be of considerable benefit to the court decision making process. A case may help illustrate some of the issues.

\section{Case of John}

John (pseudonym) is a 46-year-old Burmese American OND veteran who was diagnosed with bipolar disorder I with psychotic features. The patient's name and other identifying details have been altered to protect his confidentiality. The patient presents with medical conditions that include profound impairment and a wide range of somatic complaints that could be clinically linked to his rampant delusional network. It is unclear whether he has a family history of a thought disorder, however, he did report a family history of mental health issues (i.e., mother's depression). The patient presents with delusional beliefs that are signaled by a profound fear that everyone (i.e., especially doctors) are trying to poison him. As a result, he rigidly refuses to take psychotropic medications prescribed. He ingests Betel Nut on a regular basis. The patient's pervasive fears about being poisoned are also depicted in intrusive thoughts of these activities. Collectively, these delusions result in considerable distress and rendered it difficult for him to socialize with anyone outside of the hospital. He seeks out services through the VA and other area hospitals. He has an unfortunate reputation in the ER, pharmacy and the pain clinic as being a disruptive behavior patient. For example, he presents as demanding, extremely loud, perseverative, abrasive, and is keenly preoccupied to this fear of being poisoned. There were police responses to escort him from the hospital. Service providers in several VA units are unsure how to approach or work with patient because of his bombastic and overly demonstrative interpersonal style. Given the symptoms and situation, it would be quite beneficial for the patient to participate in group psychotherapy considering a need for an expanded psychosocial feedback loop. For example, through group therapy, the patient would be able to access more exposure to diverse veterans that would both be clinically instructive and function as a potential source of social support. This would be a process of managing psychological symptoms while also receiving normalizing feedback [29]. He has a 10-year-old son from a marriage that lasted about a year. The patient now seeks visitation but has been denied this option because he has a somewhat abrasive, argumentative, delusional and loud interpersonal style that has resulted in child protective workers not recommending him to the courts as a suitable parent. The patient has formed a new romantic relationship and secured an apartment with a room for the son. The apartment is located in the son's school district. The patient also completed parenting classes and previously entered individual therapy reasoning that these 
steps might change the CPS perceptions of him as a parent. Despite all of his conflicts with other health care providers, he does have a workable relationship with his case manager and treating psychologist who have recommended him for culturally responsive group psychotherapy as a way to clinically place him in a better position to make the case for child visitation.

The above case is consistent with some of the types of psycho-legal cases that OEF/OIF/OND veterans can present with in advance of group psychotherapy. Cases like this also illustrates that OEF/OIF/OND veterans can present with a blend of symptoms that are co-morbid. In this case, there is a significant amount of stressors associated with exposure to combat and the prevailing mental health conditions can also enhance other symptoms, such as fatigue and somatic complaints $[19,25,30]$. To little surprise, there are also predictable relational and psychological consequences stemming from these symptoms.

The focus in group treatment usually involves addressing presenting co-occurring problematic symptoms that may be relevant to issues that are stirring in the psycho-legal case of several patients in therapy together [31]. There is also a growing concern about the veteran's vulnerability to increased negative outcomes, such as offending or other legal altercations as a direct result of the complicated array of symptoms of co-occurring mental conditions [32-34].

Comorbidity prevalent in these clinical forensic cases must start with a clinician's understanding of the complete clinical picture of the psychopathology which could be applicable in group treatment [35].

Across diverse OEF/OIF/OND veterans there is a complex spectrum of disproportionally higher rates of serious mental health difficulties. The diagnostically informed clinical application of treatment in this context allows providers to more fully understand their psychosocial problems within the framework of group psychotherapy. This itself, constitutes a potentially important clinical forensic effect for court communication requirements. Providers facilitating these types of patient group treatment experiences are among the key professional informants as they communicate with the courts.

\section{Group Treatment nexus for communicating to court on behalf of veterans}

With countless examples of poor practice, it is important from the onset to stress the point that all communications from a group psychotherapist to the courts on behalf of a OEF/OIF/OND veteran are primarily clinical in nature. These provider communications are not considered forensic psychological reports. Conducting a forensic evaluation on current clinical patient would be considered an ethical breach. According to Melton, Petrila, Poythress, \& Slobogin, 2007, a forensic report has clear distinctions (e.g., goals, range of issues addressed, role of the examiner-patient and output resulting from the evaluation) [36]. By contrast, the professional role of a clinician is to provide the court with information that is directly related to the data collected or observed as a part of a veteran's treatment (i.e., couple, family, individual or group therapy). Addressing complex clinical comorbid issues such as those observed in diverse OEF/OIFOND veterans cannot be sufficiently resolved solely using group treatment.

The vast majority of OEF/OIF/OND veterans with court involvement present with mental disorders that are expected to result in stigmas that do not work in their best interests while engaged in the process of these legal matters. Mostly, a veteran's emotional distress can reflexively fuel unwanted reactions from others during critical legal contacts. However, a provider may have substantially more clinically and potentially forensically relevant information that must be shared with the court. The provider's communications to the court may or may not address the specific forensic referral question(s) being posed in reference to court. As such, providers are cautioned against going beyond the scope of what they would customarily do during the course of their routine work with a veteran in a clinical context (e.g., group psychotherapy) or actually observed while in treatment. The provider must instinctively avoid the temptation of becoming a patient advocate (i.e., offering an uninvited opinion regarding facts at issue before the court). It is also critical for the patient in this psycho-legal arena to not have an appearance that the provider could somehow be construed as engaging in an ethically questionable multiple relationship. This unwanted circumstance would significantly result in a reduction in the credibility of the provider's clinical work for the patient in question. The net effect could also result in a negative outcome for an OEF/OIF/OND veteran who as a result would not be able to use critical psychologically-relevant information that was crafted by their group psychotherapy provider.

So what kind of communications should a provider make to the courts or prepare to craft a report for this practice arena? A balanced rule of thumb approach includes providing valid evidence to support clinical findings which more often than not results in a much more credible report from the provider. For starters, a date based chronicling of key clinical events would be a strong anchor for the report. OEF/OIF/OND veterans can present for group psychotherapy with a complex symptoms including disturbances in mood, suicidal, trauma and a range of other self-destructive behaviors. The provider functioning in this clinical forensic context certainly can also state the patient's DSM-5 or ICD diagnoses as well as note any significant symptom changes overtime. Since these symptoms have often resulted in marked distress, consumed time, and interfered significantly with daily functioning in several areas (e.g., work, social, or family life) then by default they must of course be discussed in the report.

Another important clinical question that could have some relevance for the court's decision making is to what extent was there a meaningful association observed by the provider of the patient's response to group psychotherapy? Would this response be reflected in veteran behaviors while they were exposed to a diverse group of patients? This finding could potentially have even more substantive importance than the gains noted through individual therapy. In fact, the clinical report may have some psycho-legal advantages over a forensic evaluation report. For example, a provider may be able to skillfully use the report to the court as a means 
to rapidly blend large amounts of psychologically intricate information collected over months of group treatment. This type of data would assist the trier of fact in making decisions about a veteran's legal case. Where a veteran's psycholegal issues are concerned, the absence of absolute or clear and convincing truth criterion is not uncommon. However, the endogeneity between the veteran's mental health and functioning is evidenced by the turbulence contained in several areas that are expected to be more notable and certainly responsive to the experiences with their provider during a course of group psychotherapy.

\section{Are Provider Preference-Selection Treatment Factors more of a non-issue for Veterans?}

In group psychotherapy both the preference and selection of a provider are issues that can have an impact of clinical outcomes (e.g., decision to enter treatment or therapeutic motivational alliance). Provider preference-selection factors refers to the differential receiving of treatment based on patient or provider characteristics (e.g., age, gender, ethnoracial group, or sexual orientation etc.) or overlapping qualifications (e.g., doctorate or non-doctorate, veteran or non-veteran, clinical psychologist, licensed professional counselor, psychiatrists or social worker). There are many factors that can influence the experience and clinical results of group psychotherapy. Some of these factors are associated with a combination of variables including the veteran, the provider and/or the referral issues to name a few. For example, a veteran that presents with military sexual trauma may express a preference for a provider of a particular gender or race. There is no substantial body of research indicating that the gender of the provider results in substantially better clinical outcome for the patient. It is reasonable to assume that a patient enters into treatment with certain expectations as to what will transpire during these sessions. A patient who arrives to treatment with higher expectations may actually obtain better outcomes [37]. Still, far too many mental health and social services providers may struggle to comprehend the special circumstances for OEF/OIF/OND veterans presenting with clinical forensic issues contained in their cases. For example, clinical case management of the veteran can include a presenting concern, referral problem(s), comorbid psychopathology of complications, and various pending legal matters.

While the primary treatment may focus mainly on group process stages, assessment etc., there are nonetheless other forensic issues that may require the attention of the provider since they may be expected to later communicate with some legal authority. In the cases involving child custody and visitation, while a veteran may prefer to work with a particular provider, the underlying forensic issues may by default have far greater influence on the final preference-selection of a provider. In other words, the OEF/OIF/OND veteran's preference-selection decisions may be outweighed by the need to have a provider who can present the best case to the court. In this psycho-legal situation, higher provider expectations are associated with group psychotherapy especially when clinical forensic issues are of upmost concern. It remains ethically incumbent for all providers to be fully aware of and duly inform the veteran about these circumstances. In this case, a clinical forensic focus in the group may be orchestrated in a way that maximally benefits the patient and is evidenced through the documented gains observed during treatment.

While there may be professional role and treatment preferences, the degree of similarity between the veteran and provider may be less salient in clinical forensic cases. The ability to select a provider may be extremely limited because of several factors. For example, if a patient elects to participate in group, there may be only be a very short list of available providers. There are an endless list of preferred provider characteristics that are not well represented in the available at the site. All or some providers may not possess a veteran's preferred characteristics (e.g., gender, ethnoracial, former substance abuser sexual orientation, veteran, clinical expertise). For example, a disappointedly vast majority of mental health service units throughout the VA Health Care System do not have African American or Native American licensed mental health providers. In addition, the process by which some cases are assigned in the VA (e.g., BHIP team model) may also result in a provider being assigned to a provider without any consideration of a veteran's preference. If a veteran wants a particular evidence-based approach (e.g., CBT, CPT, EMDR or PET), there is no guarantee that a certified provider is available who can at least offer a particular treatment model that is ethically appropriate and culturally responsive. For example, some VA regions have a raw number of veterans waiting for evidenced-based treatments that may be very high.

\section{Ethical-legal and Culturally Responsive Considerations for Group Psychotherapy}

Providing group psychotherapy to ethnoracially diverse veterans is complex and has unending ethical demands for most licensed mental health professionals. In this case, group work is not just about the leading of an experience that promotes personal gains but also helping these therapy participants develop a form of psychological resiliency for the anticipated stresses of life [38,39]. In addition, licensed and qualified mental health professionals have an ethical obligation to minimize undue harm by protecting participants attending these group treatment sessions. For example, a patient whose comorbid mental conditions (e.g., PTSD, MDD recurrent depression and borderline personality) may make them a clinically questionable fit in group due to previous disruptive behaviors that resulted in them being dismissed from this particular treatment option. Dissatisfied with this clinical decision, the patient protested to an administrator who essentially directed the provider to admit the patient into the group where they had been originally dismissed for misconduct.

An ethical group leader is perceived as one that is culturally responsive, models desired behaviors, and maintains the highest ethical standards (e.g., respecting clinical boundaries) during all phases of their related clinical work (APA, 2010). As a result, the group members are potentially in a better position to psychologically profit from the sometimes intense cross-cultural exchanges by internalizing the observed ethical and professional behaviors modeled by the group therapist. The aforementioned patient 
actually lost a custody battle because they were unable to exercise a desired level of emotional restraint in several settings that were brought to the attention of the trier of fact during course of the case. In addition, because of this unwanted behavioral history, the group therapist for this same case was unable to provide any clinically supportive information regarding the patient's work for their case before the court.

There are cultures within cultures amongst veterans. For example, for a variety of reasons, there are sizeable pockets of patients who have conducted their own assessment of themselves or embraced the seriously uniformed clinical opinions of significant others who have ascribed a particular diagnosis to them (e.g., borderline girlfriend who inanely insists her partner has PTSD even though there is no identifiable category A traumatic event). These same patients may also have determined what course of psychological treatment they want to be used by a provider. For example, an African American veteran diagnosed with service connected PTSD from a compensation and pension disability evaluation elected to drop out of a Cognitive Processing Therapy (CPT) group after six sessions. The patient reasoned that it was easier to avoid the painful memories of various traumatic events. In this case, the patient claimed "only having depression" to which his wife agreed. The couple had been experiencing significant marital problems (e.g., moodiness and hair trigger anger outbursts) since his discharge a year ago but curiously decided after dropping out of CPT that couples therapy would "fix the problem." Self-Assessed Patients are characterized by an intense and persistent discomfort with their provider's diagnosis and/or the course of treatment prescribed by a licensed provider. For the patient there is a pervasive sense of inappropriateness for the approaches taken to address their clinically significant distress. Such a patient's stance invites an ethical counterargument that stems from the incongruence between their professed self-assessment for their clinical situation and the providers capacity or willingness to deliver their preferred treatment. These patients may challenge or actively protests the clinical work (e.g., diagnoses or mental health notes written) in an effort to either secure their insatiable need for attention or simply fulfill the drives of the comorbid functioning.

If one could ignore for the moment the fact that the patient is not a state licensed professional with extensive clinical experience, how can any provider ethically acquiesce to them without welcoming additional manipulation? Given the limited resources and long lines of mental health patients, how can a self-assessed patient's assessment be judged as a clinically necessary under these types of unwanted provider circumstances? In other words, what measures must be made to make reasonable efforts to provide ethically defensible and necessary treatments? Given a mental health provider's legal and ethical obligations, one of the questions that has arisen as a result of group therapy in these ethnoracially diverse settings is: what form of ethics training must mental health providers receive as part of their training in order to work with these types of clinical forensic patients? Ethical standards function as the rules that essentially guide the professional behavior of the clinician. Breaches or failures to comply with ethical standards can result in disciplinary action being taken by a State licensing board and/or a professional association (e.g., American Counseling Association, American Psychological Association, American Group Psychotherapy Association, or National Association of Social Workers, etc.).

Because the current paper is focused on group psychotherapy for OEF/OIF/OND veterans when forensic issues are present, the awareness of these legal issues is essential. In the end, when delivering services to diverse patients, group therapists must at a minimum remain cognizant of their ethical obligations, as delineated in the American Psychological Association's (APA) Ethical Principles of Psychologists and Code of Conduct (American Psychological Association [APA], 2010). Ethical principles are crafted to encourage the highest level of ideals and provide clinicians with a set of expectations within the profession. In addition, APA's (2010) Ethical Principles of Psychologists and Code of Conduct, instruct clinicians on the fundamental elements of group therapy. For example, the principle of beneficence and nonmaleficence encourage clinicians to take actions that are of benefit and at the same time do not increase the risk of harm to a patient.

Ethical guidelines from other professional associations may also provide more precise direction for group therapists. For example, the AGPA and IBCGP Guidelines for Ethics (2002) under 1.1 stress the relevance of providing information about the nature, risks and obligations of the group therapy [40]. The Association for Specialists in Group Work also has information that would be of considerable use to clinicians. In terms of implications, the continued access and provider credibility (i.e., trust) with OEF/ OIF/OND veterans must yield the strongest motivation for acquiring and applying the aforementioned professional ethics and recommended practices in group psychotherapy.

\section{Implications for Practice, Research, and Supervision}

There are many complex clinical forensic factors relevant to crafting group psychotherapy services that are designed to address the comorbid psychopathology of ethnoracially diverse OEF/OIF/OND veterans. Unfortunately, the clinical forensic needs for these services among OEF/OIF/OND veterans are not well described. As a mental health expert, the provider can fulfill a critical role in addressing many legal questions and thus influence the court consequences that are initiated towards a veteran. Probably one of the benefits of groups are the supportive trust relationships formed as providers work to negotiate around a veteran's comorbid psychopathology while imparting critical psycho-legal information. For example, a veteran with cognitive distortions can be moved through a provider's interventions at the same time that the collective atmosphere of other veterans function in a way that changes unwanted behaviors that undermine their case. If nothing else, the above discussion underscores the fact that if one desires to understand how to successfully deliver such services, then there must be a requisite systematized understanding of the VA 
culture, practices, clinical forensic issues and ethical issues at a minimum. From a practice viewpoint, group psychotherapists bring four important professional resources to these diverse veteran patients: (1) they possess diagnostic skills about the clinical forensic issues presented; (2) they have insights into how culturally responsive interventions can be appropriately used and (3) because a significant number of ethnoracial veterans have contacts with various courts, the previously discussed group psychotherapy services can be helpful facilitating a nexus as well as in addressing some of the natural distrust of the courts that can exist; (4) the providers must be able to craft referral specific communications (including limitations) to the court that inform triers of fact on the diverse clinical forensic issues as well as the progress made by veterans who have received group psychotherapy.

There are many future avenues for group psychotherapy clinical forensic research. This article highlighted, among many things, the need for further investigation into the overlapping issues of a group psychotherapist's cultural responsiveness, provider preferenceselection factors and outcomes. Future research, for example, might investigate further the precise role that the presence of these factors might have in functioning across different settings (e.g., home, work, and public). The same may be said for the sparse research on a veteran's provider preferences and selection. While there was scant attention given here to self-assessed patients (i.e., those patients who evaluation, diagnose and have a preferred treatment), there are many other stirring ethical and professional issues emerging from these cases for providers, administrators as well as clinical supervisors. Supervision must be culturally defined and shaped by expertise of the supervisor-supervisee as well as clinical forensic characteristics of the patients served.

On the one hand, a supervisor may need to think more carefully about how to assess the uneven competencies of the supervisee with respect to the clinical forensic issues they are expected to confront during group psychotherapy. Omitting such an assessment is more likely than not to result in overlooking important influences on the development of the supervisee and the quality of the group psychotherapy services provided. On the other hand, the strongest clinical arguments made in this article suggests a need for a possible revision of current supervision guidelines in terms of definitions, roles, ethnoracial models and frameworks of practices with respect to diverse OEF/OIFOND veterans with respect to clinical forensic matters.

\section{References}

1. Ananat, EO, Michaels G (2008) The Effect of Marital Breakup on the Income Distribution of Women with Children. J Human Resources 43: 611-29.

2. Department of Veterans Affairs and Department of Defense (2010) VA/DoD clinical practice guideline for management of post-traumatic stress 1-175.

3. Schnurr PP, Lunney CA, Bovin MJ, Marx BP (2009) Posttraumatic stress disorder and quality of life: extension of findings to veterans of the wars in Iraq and Afghanistan. Clin Psychol Rev 29: 727-35.

4. Vogt D, Smith B, Elwy R, Martin J, Schultz M, et al. (2011) Predeployment, deployment, and postdeployment risk factors for posttraumatic stress symptomatology in female and male OEF/OIF veterans. J Abnorm Psychol 120: 819-31.

5. Martindale DA, Gould JW (2004) The Forensic Model: Ethics and Scientific Methodology Applied to Custody Evaluations. J Child Custody 1: 1-22.

6. Hosek J, Kavanagh J, Miller L (2006). How Deployments Affect Service Members. Rand Corporation.

7. Cesur R, Sabia JJ, Tekin E (2013) The psychological costs of war: military combat and mental health. J Health Econ 32: 51-65.

8. Hoge CW, Auchterlonie JL, Milliken CS (2006) Mental health problems, use of mental health services, and attrition from military service after returning from deployment to Iraq or Afghanistan. JAMA 295: 1023-32.

9. Milliken CS, Auchterlonie JL, Hoge CW (2007) Longitudinal assessment of mental health problems among active and reserve component soldiers returning from the Iraq war. JAMA 298: 2141-8.

10. Tanielian T, Jaycox LH, Schell TL, Marshall GN, Burnam MA, et al. (2008) Invisible Wounds: Mental Health and Cognitive Care Needs of America’s Returning Veterans. Santa Monica, Calif, RAND Corporation.

11. Gwini SM, Forbes AB, Kelsall HL, Ikin JF, Sim MR (2015) Increased symptom reporting persists in 1990-1991 Gulf War veterans 20 years post deployment. Am J Ind Med 58: 1246-54.

12. Allen ES, Rhoades GK, Stanley SM, Markman HJ (2011) On the home front: stress for recently deployed Army couples. Fam Process 50: 235-47.

13. Goff BS, Crow JR, Reisbig AM, Hamilton S (2007) The impact of individual trauma symptoms of deployed soldiers on relationship satisfaction. J Fam Psychol 21: $344-53$.

14. Knobloch LK, Theiss JA (2011) Depressive symptoms and mechanisms of relational turbulence as predictors of relationship satisfaction among returning service members. J Fam Psychol 25: 470-8.

15. Flake EM, Davis BE, Johnson PL, Middleton LS (2009) The psychosocial effects of deployment on military children. J Dev Behav Pediatr 30: 271-8.

16. Institute of Medicine (US) (2013) Returning Home from Iraq and Afghanistan: Preliminary Assessment of Readjustment Needs of Veterans, Service Members, and Their Families. National Academies Press, US.

17. Pickett T, Rothman D, Crawford EF, Brancu M, Fairbank JA, et al. (2015). Mental Health Among Military Personnel and Veterans. North Carolina Med J 76: 299-306.

18. Trivedi RB, Post EP, Sun H, Pomerantz A, Saxon AJ, et al. (2015) Prevalence, Comorbidity, and Prognosis of Mental Health Among US Veterans. Am J Public Health 105: 2564-9.

19. Phillips KM, Clark ME, Gironda RJ, McGarity S, Kerns RW, et al. (2016) Pain and psychiatric comorbidities among two groups of Iraq and Afghanistan era Veterans. J Rehabil Res Dev 53: 413-32.

20. Maguen S, Luxton DD, Skopp NA, Gahm GA, Reger MA, et al. (2011) Killing in combat, mental health symptoms, and suicidal ideation in Iraq war veterans. J Anxiety Disord 25: 563-7.

21. Vazan P, Golub A, Bennett AS (2013) Substance Use and Other Mental Health Disorders Among Veterans Returning to the Inner City: Prevalence, Correlates, and Rates of Unmet Treatment Need. Subst Use Misuse 48: 880-93.

22. Johnson EM, Barrie KA, Possemato K, Wade M, Eaker A, et al. (2016) Predictors of Mental Health Care Utilization in Veterans With Post-Traumatic Stress Disorder Symptoms and Hazardous Drinking. Mil Med 181: 1200-6. 
23. Cifu DX, Taylor BC, Carne WF, Bidelspach D, Sayer NA, et al. (2013) Traumatic brain injury, posttraumatic stress disorder, and pain diagnoses in OIF/OEF/ OND Veterans. J Rehabil Res Dev 50: 1169-76.

24. Ramchand R, Rudavsky R, Grant S, Tanielian T, Jaycox L (2015) Prevalence of, risk factors for, and consequences of posttraumatic stress disorder and other mental health problems in military populations deployed to Iraq and Afghanistan. Curr Psychiatry Rep 17: 37.

25. Spelman JF, Hunt SC, Seal KH, Burgo-Black AL (2012) Post deployment care for returning combat veterans. J Gen Intern Med 27: $1200-9$.

26. Bagalman E (2013) Mental disorders among OEF/OIF veterans using VA health care: Facts and figures, Congressional Research Service.

27. Marmar CR (2009) Mental health impact of Afghanistan and Iraq deployment: meeting the challenge of a new generation of veterans. Depress Anxiety 26: 493-7.

28. Ford JD, Grasso DJ, Elhai JD, Courtois CA (2015) Posttraumatic Stress Disorder (2nd Edition): Scientific and Professional Dimensions Academic press.

29. Sripada RK, Bohnert KM, Ganoczy D, Blow FC, Valenstein M, et al. (2016) Initial group versus individual therapy for posttraumatic stress disorder and subsequent follow-up treatment adequacy. Psychol Serv 13: 349-55.

30. Lew HL, Vanderploeg RD, Moore DF, Schwab K, Friedman L, et al. (2008) Overlap of mild TBI and mental health conditions in returning OIF/OEF service members and veterans. J Rehabil Res Dev 45: xi-vi.

31. Krueger RF, Markon KE (2006) Reinterpreting comorbidity: a model-based approach to understanding and classifying psychopathology. Annu Rev Clin Psychol 2: 111-33.

32. Flory JD, Yehuda R (2015) Comorbidity between post-traumatic stress disorder and major depressive disorder: alternative explanations and treatment considerations. Dialogues Clin Neurosci 17: 141-50.

33. Gironda RJ, Clark ME, Ruff RL, Chait S, Craine M, et al. (2009) Traumatic brain injury, polytrauma, and pain: challenges and treatment strategies for the polytrauma rehabilitation. Rehabil Psychol 54: 247-58.

34. Ogloff JR, Talevski D, Lemphers A, Wood M, Simmons M (2015) Co-occurring mental illness, substance use disorders, and antisocial personality disorder among clients of forensic mental health services. Psychiatr Rehabil J 38: 16-23.

35. Ruscio AM (2009) Integrating Structural and Epidemiological Research to Inform the Classification of Psychopathology. Int J Methods Psychiatr Res 18: 24050 .

36. Melton GB, Petrila J, Poythress NG, Slobogin C (2007) Psychological Evaluations for the Courts (3rd Edition): A Handbook for Mental Health Professionals and Lawyers. Guilford Press.

37. Constantino MJ, Arnkoff DB, Glass CR, Ametrano RM, Smith JZ (2011) Expectations. J Clin Psychol 67: 184-92.

38. Greene LR, Harpaz-Rotem I, Sanders KA, MacGregor K, Wheat A, et al. (2014) Group treatments within the Department of Veterans Affairs: An update. In DeLucia-Waack J, Kalodner C, Riva M, The handbook of group counseling and psychotherapy (2nd Edition). Thousand Oaks, CA: Sage.

39. Gang-shun Z, Zhi-jie S, Yan-qing Z (2014) Review of Group Cognitive Behavioral Therapy for Posttraumatic Stress Disorder. Chinese J Clin Psychol 22: 560-3. 40. AGPA and IBCGP Guidelines for Ethics (2002).

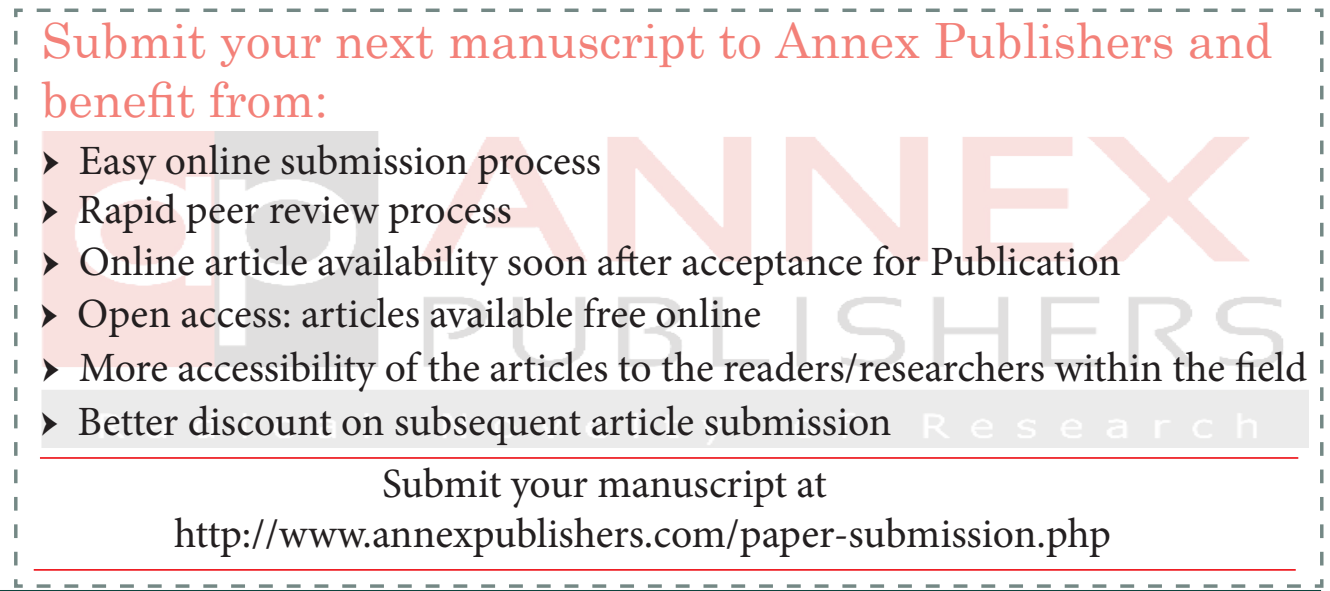

